\section{Cureus}

Received 06/02/2016

Review began 06/07/2016

Review ended 07/06/2016

Published 07/11/2016

\section{(C) Copyright 2016}

Xia et al. This is an open access article distributed under the terms of the Creative Commons Attribution License CC-BY 3.0., which permits unrestricted use, distribution, and reproduction in any medium, provided the original author and source are credited.

\title{
A Treatment Planning Study of Stereotactic Body Radiotherapy for Atrial Fibrillation
}

\author{
Ping Xia ${ }^{1}$, Rupesh Kotecha ${ }^{1}$, Naveen Sharma ${ }^{1}$, Martin Andrews ${ }^{1}$, Kevin L. Stephans ${ }^{1}$, \\ Carlos Oberti $^{2}$, Sara Lin ${ }^{1}$, Oussama Wazni ${ }^{2}$, Patrick Tchou ${ }^{3}$, Walid I. Saliba ${ }^{2}$, John Suh ${ }^{4}$ \\ 1. Department of Radiation Oncology, Cleveland Clinic 2. Department of Cardiovascular Medicine, \\ Cleveland Clinic 3. Department of Cardiovascular Medicine, Cleveland 4. Cleveland Clinic
}

$\square$ Corresponding author: Ping Xia, xiap@ccf.org

Disclosures can be found in Additional Information at the end of the article

\section{Abstract}

Purpose: To explore the feasibility of using stereotactic body radiotherapy (SBRT) to irradiate the antra of the four pulmonary veins while protecting nearby critical organs, such as the esophagus.

Materials and Methods: Twenty patients who underwent radiofrequency catheter ablation for atrial fibrillation were selected. For each patient, the antra of the four pulmonary veins were identified as the target volumes on a pre-catheterization contrast or non-contrast CT scan. On each CT scan, the esophagus, trachea, heart, and total lung were delineated and the esophagus was identified as the critical organ. For each patient, three treatment plans were designed with 0,2 , and $5 \mathrm{~mm}$ planning margins around the targets while avoiding overlap with a planning organ at risk volume (PRV) generated by a $2 \mathrm{~mm}$ expansion of the esophagus. Using three noncoplanar volumetric modulated arcs (VMAT), 60 plans were created to deliver a prescription dose of $50 \mathrm{~Gy}$ in five fractions, following the SBRT dose regimen for central lung tumors. With greater than $97 \%$ of the planning target volumes (PTV) receiving the prescription doses, we examined dosimetry to $0.03 \mathrm{cc}$ and $5 \mathrm{cc}$ of the esophagus PRV volume as well as other contoured structures.

Results: The average PTV-0 mm, PTV-2 mm, and PTV-5 mm volumes were $3.05 \pm 1.90 \mathrm{cc}, 14.70$ $\pm 5.00 \mathrm{cc}$, and $40.85 \pm 10.20 \mathrm{cc}$, respectively. With three non-coplanar VMAT arcs, the average conformality indices (ratio of prescription isodose volume to the PTV volume) for the PTV-0 $\mathrm{mm}, \mathrm{PTV}-2 \mathrm{~mm}$ and PTV-5 mm were $4.81 \pm 2.0,1.71 \pm 0.19$, and $1.23 \pm 0.08$, respectively. Assuming patients were treated under breath-hold with $2 \mathrm{~mm}$ planning margins to account for cardiac motion, all plans met esophageal PRV maximum dose limits $<50$ Gy to 0.03 cc and 16 plans (80\%) met < 27.5 Gy to 5 cc of the esophageal PRVs. For PTV- 5 mm plans, 18 plans met the maximum dose limit < 50 Gy to $0.03 \mathrm{cc}$ and only two plans met the maximum dose limit $<27.5$ Gy to 5 cc of the esophageal PRV.

Conclusions: The anatomical relationship between the antra of the four pulmonary veins and the esophagus varies from patient to patient. Adding $2 \mathrm{~mm}$ planning margins and a $2 \mathrm{~mm}$ PRV to the esophagus can meet the dose constraints developed for SBRT central lung tumors. Future studies are needed to validate the safety and efficacy of the planning dose, tolerance dose to normal cardiac tissue, and adequate planning margins.

Categories: Cardiology, Radiation Oncology

Keywords: stereotactic body radiotherapy, atrial fibrillation, treatment planning, hypofractionation, radiotherapy 


\section{Introduction}

Atrial fibrillation is the most common arrhythmia encountered in medical practice and is a growing global health concern with a 19\% increase over the last 20 years and 5 million new cases diagnosed each year worldwide [1-3]. In the United States, it is estimated that 2.3 million adults are diagnosed with atrial fibrillation. This number is projected to increase to 5.6 million by 2050 with more than $50 \%$ of patients being 80 years or older [4]. For patients who are treated for rhythm control, treatment options include medical therapies aimed at suppressing the arrhythmia or an ablative procedure to destroy the arrhythmogenic source itself. For atrial fibrillation cases that are refractory to medical therapy, catheter ablation (CA) through either radiofrequency or cryothermy is an important treatment option. The aim of the procedure is to eliminate the arrhythmogenic tissue by either heating (radiofrequency) or cooling (cryothermy) [2]. Similarly, using X-rays, stereotactic radiosurgery (SRS) can eliminate arrhythmogenic tissue. Stereotactic radiosurgery has a long history of successful treatment for non-cancer conditions, such as trigeminal neuralgia and arteriovenous malformations [5].

Major complications and even death with CA procedures are risks [2, 6-8]. The procedures are experience-dependent, invasive, and complex. For predominantly younger and healthier patients, the reported major complications occurring during the ablation procedures are approximately $5 \%$ [2, 6-8]. However, for elderly patients with other medical comorbidities, the risks of the procedures may be even higher [2, 6-8].

Using focused radiation for patients with medically inoperable early-stage lung cancer, stereotactic body radiosurgery (SBRT) has achieved excellent local control [9-10]. It is postulated that for patients with refractory atrial fibrillation and other medical comorbidities, for whom the CA procedure may pose a high risk, SRS may be an alternative option of treatment [11]. The SRS procedure is a non-invasive, outpatient procedure. With a CyberKnife platform, the feasibility of SRS was tested on scar tissue creation in the cavotricuspid isthmus and pulmonary vein atria in normal swine models [11]. Using a single patient image data set, Ipsen, et al. [12] conducted a single fraction planning study with variable planning margins to compensate for breathing motion observed on real-time MRI. Using patient CT images acquired for the CA procedures, we conducted a feasibility treatment planning analysis with multiple fractionations similar to stereotactic body radiation to explore whether the esophagus dose constraints for SBRT lung treatment can be achieved.

The treatment volumes defined for this planning study mimic volumes of CA, which are in anatomical proximity to the esophagus. The objective of this planning study is to investigate what planning margins can safely accommodate the esophagus tolerance dose using clinically derived SBRT dose constraints to the esophagus for centrally located early-stage lung cancer [13-15] while accounting for cardiac and respiratory motion.

The study was approved by the Cleveland Clinic Institutional Review Board, protocol \# 15-005. A waiver of informed patient consent was approved for the study.

\section{Materials And Methods}

\section{Delineation of target volumes and critical organs}

Twenty patients who underwent radiofrequency CA for atrial fibrillation were randomly selected. For each patient, the antra of the four pulmonary veins were identified as the target volume on the pre-catheterization contrast or non-contrast CT scan. On each CT scan, the esophagus, trachea, heart, and total lung were delineated with the esophagus identified as the critical organ. The esophagus was uniformly expanded by $2 \mathrm{~mm}$ to create the planning organat-risk volume (PRV) in order to account for residual respiratory and cardiac motion-induced 
esophageal motion. The physical density of the contrast agents administered during acquisition of the planning CT was overridden to $1.0 \mathrm{~g} / \mathrm{cm}^{3}$ because no contrast agent would be administered during treatment.

\section{Radiation dose}

For patients with early-stage, non-small cell, centrally located lung cancers, the esophagus volume dose constraints from the Radiation Therapy Oncology Group (RTOG) 0813 [14] are a maximum point dose of $52.5 \mathrm{~Gy}$ and a $5 \mathrm{cc}$ dose limit of $27.5 \mathrm{~Gy}$. Our previous clinical experience found no significant late esophageal toxicity when the esophageal point dose (to 0.03 cc of the volume) was less than $50 \mathrm{~Gy}$ and the dose to $1 \mathrm{cc}$ of the esophagus volume was less than 45 Gy [15]. Because of heart motion and the potential displacement of the esophagus, we applied these dose constraints to the esophagus PRV instead of the esophagus itself. These dose limits were based on the five fraction scheme with a prescription of $50 \mathrm{~Gy}$. Previous preclinical studies $[11,16]$ showed that a single fraction of $32.5 \mathrm{~Gy}$ was necessary to achieve transmural scarring of the myocardium, similar to CA. Directly applying a linear-quadratic (LQ) model with alpha/beta ratios of $3 \mathrm{~Gy}$ (late effect) and $10 \mathrm{~Gy}, 32.5 \mathrm{~Gy}$ in a single fraction is equivalent to $230.75 \mathrm{~Gy}$ and $115.1 \mathrm{~Gy}$ in 2 Gy per fraction, respectively. It is, however, known that the LQ model may over-estimate the total dose in fraction size > 8-10 Gy [17]. Alternatively, radiobiological modeling studies have determined that a biological effective dose (BED) of $34 \mathrm{~Gy}$ in a single fraction is equivalent to $48 \mathrm{~Gy}$ in four fractions [18-19]. We, therefore, chose a prescription dose of $50 \mathrm{~Gy}$ in five fractions, for which we have esophageal clinical tolerance dose experience.

\section{Planning technique}

For each patient, three treatment plans were designed with 0,2 , and $5 \mathrm{~mm}$ planning margins to the target volumes (referred to as PTV-0 mm, PTV- $2 \mathrm{~mm}$, and PTV- $5 \mathrm{~mm}$, respectively) while avoiding overlaps of the esophagus PRVs. Three non-coplanar volumetric modulated arcs (VMAT) were utilized for each plan with a full arc at the couch angle of $0^{\circ}$, a partial arc (from $40^{\circ}$ to $182^{\circ}$ ) at the couch angle of $20^{\circ}$, and a partial arc (from $320^{\circ}$ to $178^{\circ}$ ) at the couch angle of $340^{\circ}$. A total of 60 plans were created utilizing the automatic planning module in the Pinnacle treatment planning system (Philips Radiation Oncology Systems, Fitchburg, WI). To create a highly conformal plan with the auto-planning module, we expanded each PTV by an additional $2 \mathrm{~mm}$ and $2 \mathrm{~cm}$, named as PTVs_2 mm and PTVs_2 cm, respectively. From the PTVs_2 cm, we created a ring structure of $2 \mathrm{~cm}$, named $2 \mathrm{~cm}$ _ring. For all PTVs, the planning dose objectives used for the auto-planning module are listed in Table 1. These planning objectives were applied to all 60 plans. Because of small PTVs, the final dose calculation resolution was $2 \mathrm{~mm}$ using the collapsed cone convolution algorithm. A high-definition multileaf collimator was used for beam shaping with a minimum leaf width of $0.25 \mathrm{~cm}$. 


\section{Cureus}

\begin{tabular}{|c|c|c|c|c|c|}
\hline ROI & Type & Dose (Gy) & Vol (\%) & Priority & Compromise \\
\hline PTV-2 mm & Target & 50 & & & \\
\hline 2 mm_Ring & Mean Dose & 45 & & High & Allow \\
\hline 5 mm_Ring & Max Dose & 40 & & High & Allow \\
\hline 2 cm_Ring & Max Dose & 22 & & High & Allow \\
\hline Esophagus_2 mm PRV & Max Dose & 40 & & High & Allow \\
\hline Esophagus_2 mm PRV & Max DVH & 35 & $5 \%$ & High & Allow \\
\hline Esophagus & Max Dose & 48 & & High & Allow \\
\hline Spinal Cord & Max Dose & 15 & & High & Allow \\
\hline Spinal Cord & Max DVH & 13 & $3 \%$ & High & Allow \\
\hline
\end{tabular}

TABLE 1: An Example of Planning Dose Objective Input into the Auto-Planning for PTV-2 mm Plans

$\mathrm{ROI}$ = region of interest; $\mathrm{DVH}=$ dose volume histogram; $\mathrm{PTV}=$ planning target volume, $\mathrm{PRV}=$ planning organ at risk volume

\section{Plan evaluations}

With greater than $97 \%$ of the planning target volumes receiving the prescription dose of $50 \mathrm{~Gy}$, the planning constraints for the esophagus PRV were set as: maximum dose to $0.03 \mathrm{cc}<50 \mathrm{~Gy}, 1$ cc $<45$ Gy, 2 cc $<33.5$ Gy, and 5 cc of the esophagus PRV $<27.5 \mathrm{~Gy}$. It should be noted these dose constraints from RTOG 0813 [14] and other studies [13, 15, 20-21] were applied to the esophagus, not the esophagus PRV. Because of cardiac motion, we applied these dose constraints conservatively. Multiply defined endpoint doses to other sensitive structures, such as the heart, aorta, left atrium, trachea, lung, and spinal cord, were reported as well.

\section{Results}

In the human heart, the left atrium is immediately anterior to the esophagus and the pulmonary veins are in close proximity to the esophagus. The anatomical relationship between the target and the esophagus varies from patient to patient, as listed in Table 2 . Figure $1 \mathrm{~A}-1 \mathrm{C}$ shows three examples of anatomic variations between the target and the esophagus. In Figure $1 A-1 C$, the esophagus had overlapped or was within a short distance to the target on the (a) left side, (b) centrally, and (c) right side. Among 20 patients, 15 patients (75\%) had target volumes that overlapped with the esophagus $2 \mathrm{~mm}$ PRV, and five patients (25\%) had a minimum distance that varied from $1 \mathrm{~mm}$ to $5.7 \mathrm{~mm}$. The majority of patients (13 out 20,65\%) had an overlap or the shortest distance occurring on the left side, four patients on the right side, and three patients centrally. Figure $2 A-2 C$ shows examples of dose distributions in three dimensions and dose-volume histograms for a selected patient dataset. Among 20 patient datasets, the average PTV-0 mm, PTV- $2 \mathrm{~mm}$, and PTV-5 mm volumes were $3.05 \pm 1.90 \mathrm{cc}, 14.70 \pm 5.00 \mathrm{cc}$, and $40.85 \pm$ $10.20 \mathrm{cc}$ (mean \pm standard deviation), respectively. With three non-coplanar VMAT arcs, the 


\section{Cureus}

average conformality indices (ratio of prescription isodose volume to the PTV volume) for PTV$0 \mathrm{~mm}$, PTV- $2 \mathrm{~mm}$, and PTV-5 $\mathrm{mm}$ were $4.81 \pm 2.0,1.71 \pm 0.19$, and $1.23 \pm 0.08$, respectively.

\begin{tabular}{|c|c|c|}
\hline Patient ID & Distance (mm) & Side \\
\hline 1 & Overlap & Central \\
\hline 2 & Overlap & $\mathrm{L}$ \\
\hline 3 & 5.7 & L \\
\hline 4 & Overlap & L \\
\hline 5 & Overlap & L \\
\hline 6 & Overlap & $\mathrm{L}$ \\
\hline 7 & Overlap & $\mathrm{R}$ \\
\hline 8 & 1.8 & $\mathrm{~L}$ \\
\hline 9 & 2.6 & L \\
\hline 10 & Overlap & L \\
\hline 11 & 2.7 & $\mathrm{~L}$ \\
\hline 12 & Overlap & $\mathrm{L}$ \\
\hline 13 & Overlap & $\mathrm{L}$ \\
\hline 14 & 1.0 & $\mathrm{R}$ \\
\hline 15 & Overlap & Central \\
\hline 16 & Overlap & L \\
\hline 17 & Overlap & Central \\
\hline 18 & Overlap & $\mathrm{L}$ \\
\hline 19 & Overlap & $\mathrm{R}$ \\
\hline 20 & Overlap & R \\
\hline
\end{tabular}

TABLE 2: Anatomical Relationship Variations Between the Esophagus and the Target Volume 


\section{Cureus}

(a)

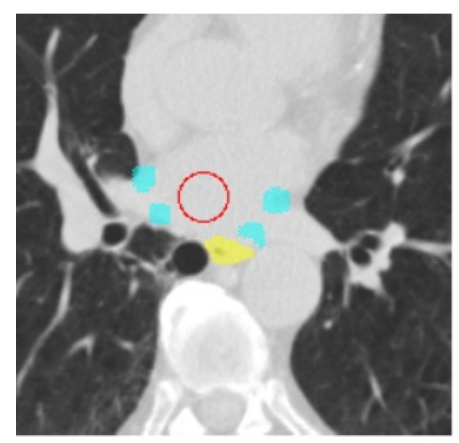

Left side (b)

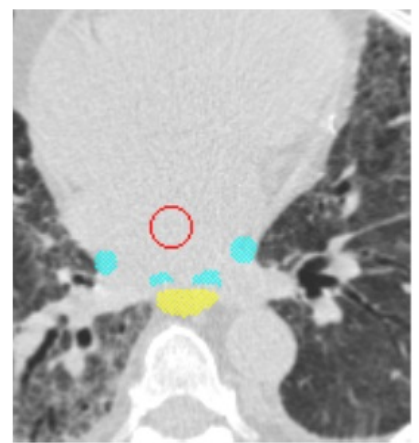

Central (c)

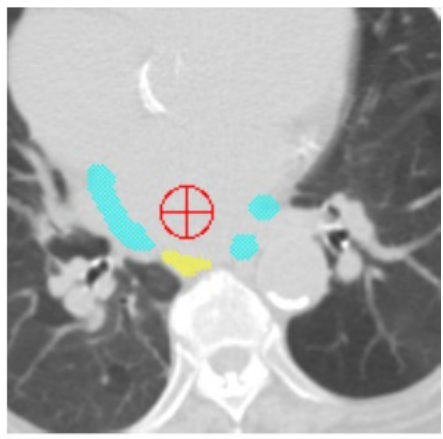

Right side

FIGURE 1: The esophagus had overlapped or was within a short distance to the target on the (a) left side, (b) centrally, and (c) right side.

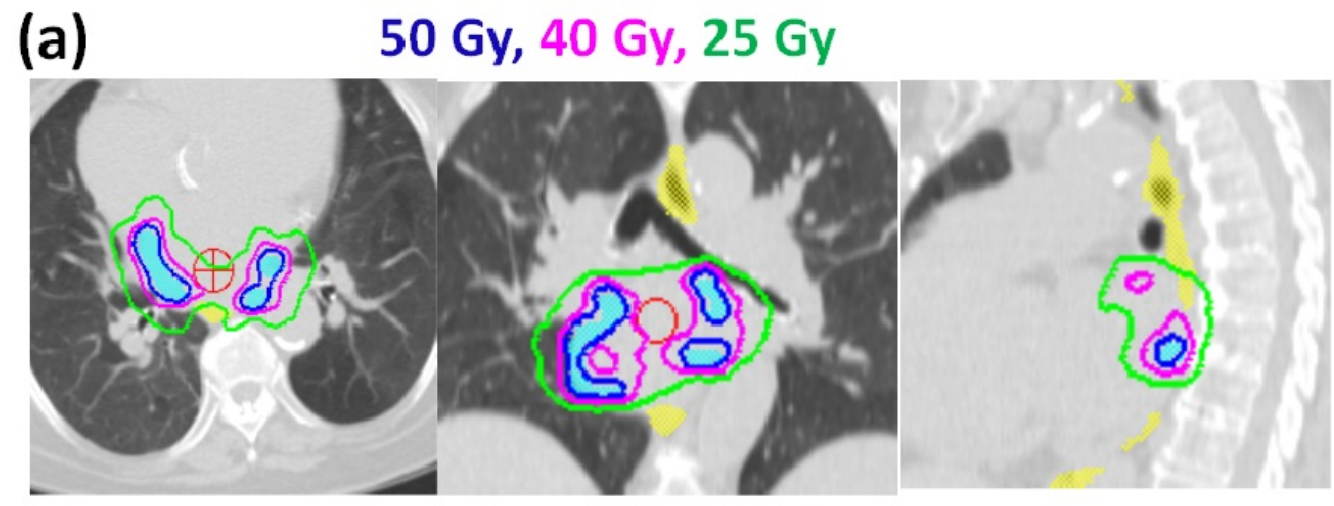

(b)

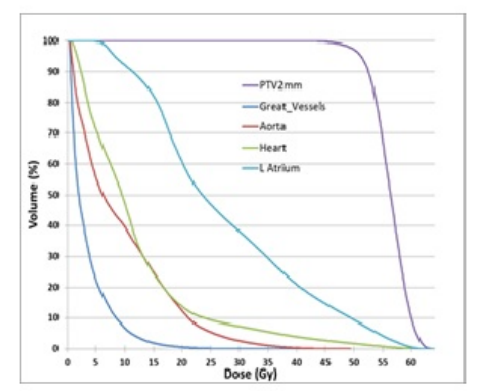

(c)

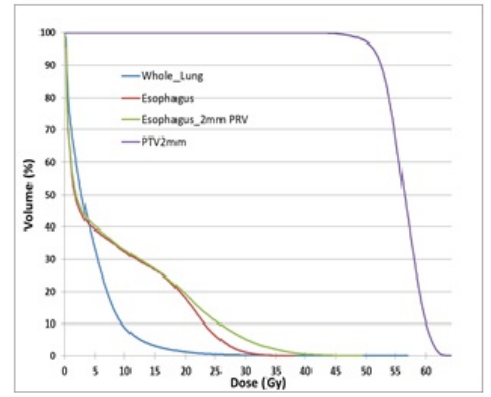

FIGURE 2: A) Three-dimensional dose distributions for a selected patient and B-C) dose volume histograms. 
esophagus PRV and their standard deviations for PTV-0 mm, PTV-2 mm, and PTV-5 mm plans. Table 3 lists the number of plans that exceeded the dose limits of D0.03 cc < $50 \mathrm{~Gy}$, D1 cc < 45 Gy, D2 cc < 33.5, and D5 cc < 27.5 Gy. Because all plans were normalized to have $97 \%$ of the PTVs receiving the prescription dose of $50 \mathrm{~Gy}$, PTV-0 mm plans had the smallest PTV volumes, resulting in the highest D0.03 cc for the esophagus and esophagus $2 \mathrm{~mm}$ PRV when compared to those in PTV-2 mm and PTV-5 mm plans. If the patients were treated during breath-hold using $2 \mathrm{~mm}$ planning margins to account for the cardiac motion, all PTV-2 $\mathrm{mm}$ plans would meet the esophageal dose limits of D0.03 cc < 50 Gy, D1 cc < 45 Gy, D2 cc < 33.5 Gy, and D5 cc < 27.5 Gy. For the esophagus PRV, dose limits for D0.03 cc and D1 cc were met by all plans, but the dose limits for D2 cc and D5 cc were exceeded by eight (40\%) plans and four plans (80\%), respectively.
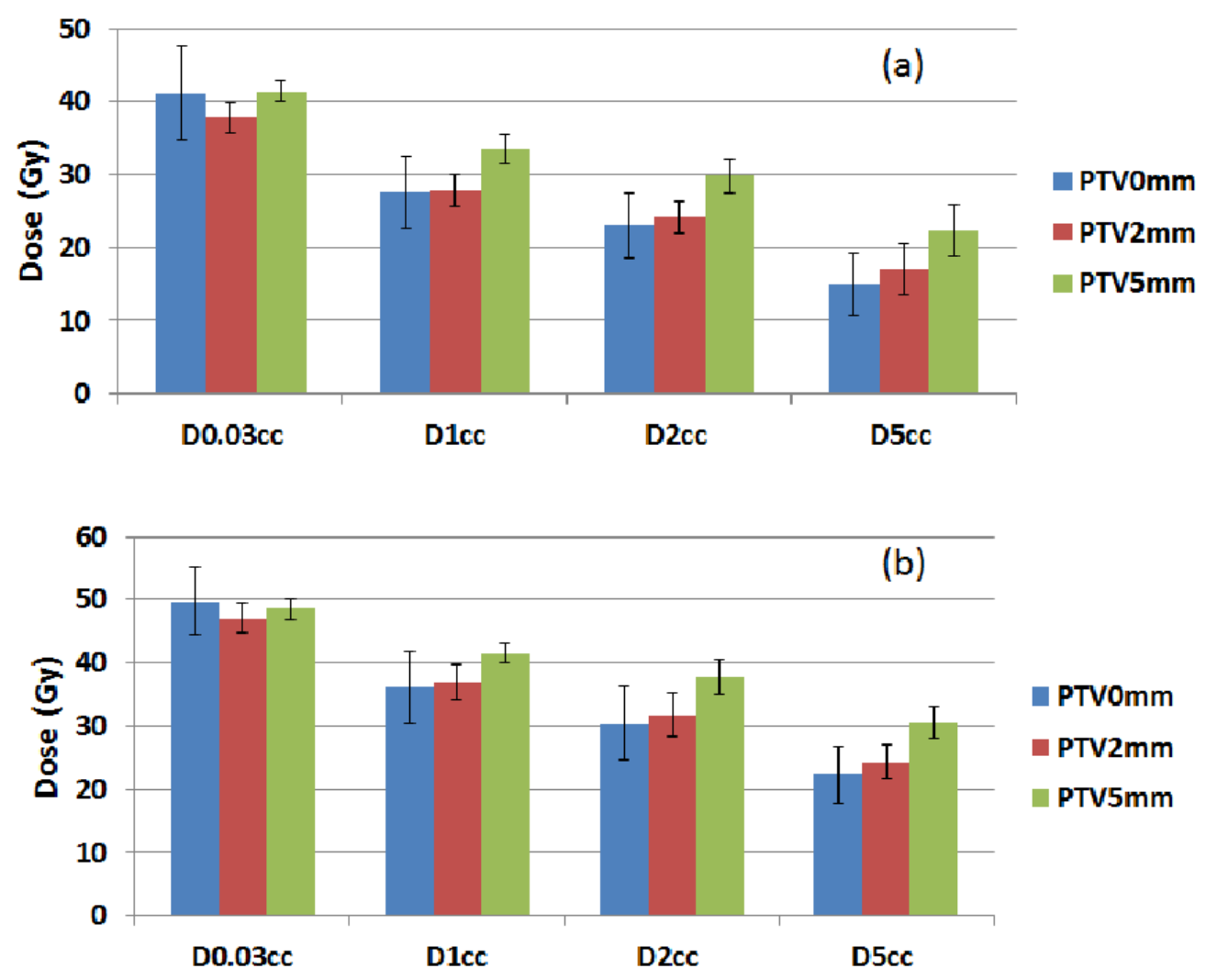

FIGURE 3: A) The average doses of D0.03 cc, D1 cc, D2 cc, and D5 cc of esophagus and B) esophagus PRV and their standard deviations for PTV-0 mm, PTV-2 mm, and PTV-5 mm plans. 


\section{Cureus}

\begin{tabular}{|c|c|c|c|c|c|c|c|c|c|}
\hline & \multirow[b]{2}{*}{ End Point } & \multicolumn{4}{|c|}{ Esophagus } & \multicolumn{4}{|c|}{ Esophagus 2 mm PRV } \\
\hline & & D0.03 cc & D1 cc & D2 cc & D5 cc & D0.03 cc & D1 cc & $\mathrm{D} 2 \mathrm{cc}$ & D5 cc \\
\hline & Dose Limits & $<50$ Gy & $\begin{array}{l}<45 \\
\text { Gy }\end{array}$ & $\begin{array}{l}<33.5 \\
\text { Gy }\end{array}$ & $\begin{array}{l}<27.5 \\
\text { Gy }\end{array}$ & $<50$ Gy & $\begin{array}{l}<45 \\
\text { Gy }\end{array}$ & $\begin{array}{l}<33.5 \\
\text { Gy }\end{array}$ & $\begin{array}{l}<27.5 \\
\text { Gy }\end{array}$ \\
\hline $\begin{array}{l}\text { PTV-0 } \\
\mathrm{mm}\end{array}$ & $\begin{array}{l}\text { \# plans } \\
\text { exceeded }\end{array}$ & 0 & 0 & 0 & 0 & 14 & 0 & 7 & 1 \\
\hline $\begin{array}{l}\text { PTV-2 } \\
\mathrm{mm}\end{array}$ & $\begin{array}{l}\text { \# plans } \\
\text { exceeded }\end{array}$ & 0 & 0 & 0 & 0 & 0 & 0 & 8 & 4 \\
\hline $\begin{array}{l}\text { PTV-5 } \\
\mathrm{mm}\end{array}$ & $\begin{array}{l}\text { \# plans } \\
\text { exceeded }\end{array}$ & 0 & 0 & 1 & 2 & 2 & 0 & 19 & 18 \\
\hline $\begin{array}{l}\text { TABLE } \\
\text { mm PF }\end{array}$ & $\begin{array}{l}\text { A Summar } \\
\text { Dose Toler }\end{array}$ & $\begin{array}{l}\text { f the Nu } \\
\text { e Amon }\end{array}$ & $\begin{array}{l}\text { mber } \\
\text { g PTV }\end{array}$ & $\begin{array}{l}\text { f Plans } \\
\text { mm, }\end{array}$ & $\begin{array}{l}\text { xceec } \\
\text { rV-2 m }\end{array}$ & $\begin{array}{l}\text { Esophe } \\
\text { and PT }\end{array}$ & $\begin{array}{l}\text { agus a } \\
\text { V-5 mr }\end{array}$ & $\begin{array}{l}\text { nd Eso } \\
\text { Plans }\end{array}$ & hagus \\
\hline
\end{tabular}

Figure $4 \mathrm{~A}$ shows the average maximum doses (defined as D0.03 cc to all structures, except the spinal cord, which is defined as the dose to $0.35 \mathrm{cc}$ ) to the aorta, great vessels, heart, left atrium, spinal cord, and trachea and their standard deviations for PTV-0 mm, PTV-2 mm, and PTV-5 $\mathrm{mm}$ plans. Figure $4 B$ shows the average specified volume doses to the aorta, great vessels, heart, left atrium, trachea, and total lung and their standard deviations for PTV-0 mm, PTV-2 $\mathrm{mm}$, and PTV-5 mm plans. According to the report of the American Association of Physicists in Medicine (AAPM) Task Group 101, tolerance doses to other normal tissues were listed in Table 4 and the number of PTV-2 mm plans, which exceeded the listed tolerance, were also listed [19]. 


\section{Cureus}
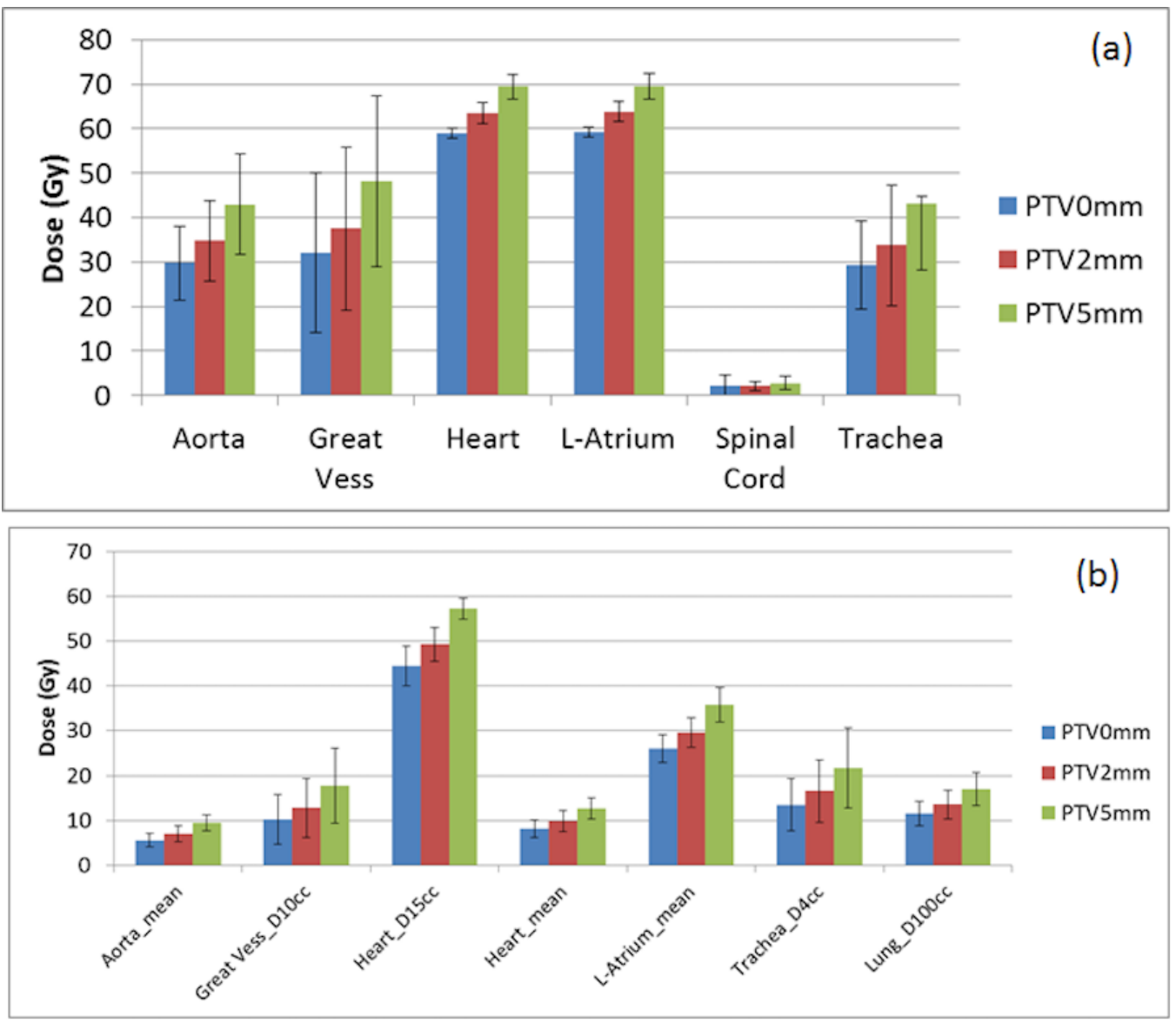

FIGURE 4: A) The average maximum doses and B) the average volume specified doses to listed organs and their standard deviations. 


\section{Cureus}

\begin{tabular}{|c|c|c|}
\hline \multirow{2}{*}{ ROI } & \multirow{2}{*}{ Endpoint } & \# Plans \\
\hline & & Exceeded \\
\hline Aorta & $\mathrm{D} 0.03 \mathrm{cc}$ & NA \\
\hline Aorta & Dmean & NA \\
\hline Great Vessels & D0.03 cc < 53 Gy & 4 \\
\hline Great Vessels & D10 cc < 47 Gy & 0 \\
\hline Heart & D0.03 cc < 38 Gy & 20 \\
\hline Heart & $\mathrm{D} 15 \mathrm{cc}<32 \mathrm{~Gy}$ & 20 \\
\hline Heart & Dmean & NA \\
\hline L Atrium & D0.03 cc & NA \\
\hline L Atrium & Dmean & NA \\
\hline Spinal Cord & D0.35 cc < 23 Gy & 0 \\
\hline Trachea & D0.03 cc < 40 Gy & 5 \\
\hline Trachea & D4 cc < 16.5 Gy & 10 \\
\hline Whole Lung & D100 cc < 13.5 Gy & 10 \\
\hline
\end{tabular}

\section{TABLE 4: A Summary of the Number of PTV-2 mm Plans Exceeded Tolerance Doses of AAPM TG 101}

$\mathrm{ROI}$ - region of interest

\section{Discussion}

In this paper, we conducted a treatment planning study to explore a potential new application of stereotactic body radiation therapy for atrial fibrillation. The major technical challenges in irradiating cardiac-targeted tissue are the management of breathing and cardiac motions and unknown radiation toxicities to normal cardiac tissues, such as the aorta, great vessels, atria, and heart, after hypofractionated radiation. Among all organs at risk, we identified the esophagus as the most critical organ for the treatment of atrial fibrillation with focused radiation due to its proximity to the radiation target volume while documenting the radiation dose to other normal organs. Following our clinical SBRT experience for early stage centrally located lung tumors, we chose a prescription dose of $50 \mathrm{~Gy}$ in five fractions, for which we have clinical esophageal dose tolerance experience [15]. In this series, we found no significant late esophageal toxicity when the dose limits for the maximum dose (D0.03 cc) < 50 Gy and D1cc < $45 \mathrm{~Gy}$ were met. Other studies suggested the dose limits to D2 cc and D5 cc for the esophagus, although the correlation between late esophagus toxicity and dose limits to D2 cc (<33.5 Gy) and D5 cc $(<27.5 \mathrm{~Gy})$ of the esophagus were not conclusive [13-15, 20-21]. With the maximum dose limits (D0.03 cc < 50 Gy and D1cc < 45 Gy), we found that the PTV-2 mm plans may provide adequate protection to the esophagus while a $2 \mathrm{~mm}$ PTV margin may be a reasonable 
magnitude to account for the heart motion.

Concerning cardiac motion and radiation dose delivery precision, Gardner, et al. implanted thermoluminescent dosimeter (TLD) crystals onto the surface of canine hearts and transferred metal-oxide-semiconductor field-effect transistor (MOSFET) sensors via a catheter in canine and porcine models close to an ablation target volume to measure the difference between the delivered and planned radiation doses [23]. Planned with an internal left atrium target volume derived from cardiac-gated CT scans, they found the measured doses were within $10 \%$ of the planned doses using either of the dose-monitoring techniques. Additional research also demonstrates that radiosurgical targeting of cardiac motion is, in fact, more predictable than respiratory motion [24]. Real-time MRI scans of healthy individuals have revealed that left atrial motion is $7.8 \mathrm{~mm}$ in the superior, $1.6 \mathrm{~mm}$ in anterior, and $0.7 \mathrm{~mm}$ in the left direction. In our study, we did not have cardiac-gated CT images for these patients but simply applied uniform margins of $2 \mathrm{~mm}$ and $5 \mathrm{~mm}$. Considering a quadratic relationship between the organ motion and treatment set-up uncertainties, the $2 \mathrm{~mm}$ planning margin can adequately account for $1.6 \mathrm{~mm}$ cardiac motion in anterior-posterior and lateral directions and $1 \mathrm{~mm}$ setup uncertainty. However, the real-time MRI study [24] was performed during a normal heartbeat, likely different from the irregular motion for patients with atrial fibrillation.

The rhythm of cardiac motion for patients with atrial fibrillation can be unpredictable, but the motion magnitude may be similar to healthy patients. In this study, we assumed that the respiratory motion could be perfectly controlled under active breathing motion control and assumed a perfect patient set-up for five daily treatments. These assumptions might be difficult to achieve clinically. On the other hand, if we further expanded the PTV margin to $5 \mathrm{~mm}$, taking into account the cardiac motion, imperfect breathing motion control, and uncertainties in daily patient set-up, then two PTV-5 mm plans would exceed the maximum dose limit of D0.03 cc < 50 Gy and most PTV-5 mm plans would exceed the D2 cc and D5 cc dose limits to the $2 \mathrm{~mm}$ PRV esophagus. Because automated treatment planning was used for this study, it is also possible than an experienced human planner could further reduce the dose to the esophageal PRV while maintaining target coverage.

In a future study, non-uniform planning margins may be considered, especially to increase the planning margins in the superior and inferior directions. Since the shortest distance between the esophagus and the targets are in the anterior and posterior directions, we do not anticipate a drastic increase in the esophagus dose by increasing a superior-inferior planning margin in the targets. The doses to other normal structures may increase, which will require further investigation. Since the radiation target volumes in the present study modeled CA, a potential alternative would be redefining the target volume distance away from the esophagus while still achieving the treatment goal of transmural scarring of the myocardium.

Directly applying an esophageal toxicity profile from cancer patients to non-cancer patients is subject to debate as we often do not know the late normal tissue toxicities for cancer patients. The best data we have for cardiac toxicity is from the report of the American Association of Physicists in Medicine (AAPM) Task Group 101 [22]. As the authors of the report pointed out, the suggested tolerance doses to these normal tissues are not fully validated and only serve as a first approximation. A recent study on the rectal toxicity from SBRT prostate treatment indicated that for a tubular structure, such as the rectum and esophagus, instead of a volume dose, the radiation dose to the circumference of the structure may be a better prediction of toxicity because of the ability of repair by the adjacent stem cells [25]. Our future study will also report on the esophagus circumference dose. Furthermore, the tolerance doses to other substructures of the heart, such as the aorta, left atrium, ventricles, and mitral valves, were not listed in the AAPM Task Group 101 report and, therefore, requires further investigation [22]. 


\section{Conclusions}

The anatomical relationship between the antra of the four pulmonary veins and the esophagus varies from patient to patient. Adding $2 \mathrm{~mm}$ planning margins and a $2 \mathrm{~mm}$ PRV to the esophagus can meet the dose constraints developed for SBRT central lung tumors. Future studies are needed to explore different target volume strategies to validate the safety and efficacy of the planning dose to the target volumes, the tolerance doses to the normal cardiac tissue, and adequate planning margins.

\section{Additional Information \\ Disclosures}

Human subjects: Consent was obtained by all participants in this study. The study was approved by Cleveland Clinic Institutional Review Board. issued approval Protocol \# 15-005. A waiver of informed consent was approved for the study. Animal subjects: All authors have confirmed that this study did not involve animal subjects or tissue. Conflicts of interest: In compliance with the ICMJE uniform disclosure form, all authors declare the following:

Payment/services info: All authors have declared that no financial support was received from any organization for the submitted work. Financial relationships: Ping Xia declare(s) a grant from Philips. John Suh declare(s) a grant and personal fees from Varian and Elekta. Other relationships: All authors have declared that there are no other relationships or activities that could appear to have influenced the submitted work.

\section{References}

1. Chugh SS, Havmoeller R, Narayanan K, Singh D, Rienstra M, Benjamin EJ, Gillum RF, Kim YH, McAnulty JH Jr, Zheng ZJ, Forouzanfar MH, Naghavi M, Mensah GA, Ezzati M, Murray CJ: Worldwide epidemiology of atrial fibrillation: A Global Burden of Disease 2010 study . Circulation. 2014, 129:837-47. 10.1161/CIRCULATIONAHA.113.005119

2. Maan A, Shaikh AY, Mansour M, Ruskin JN, Heist EK: Complications from catheter ablation of atrial fibrillation: a systematic review. Crit Pathw Cardiol. 2011, 10:76-83.

10.1097/HPC.0b013e318224b7bd

3. Naccarelli GV, Varker H, Lin J, Schulman KL: Increasing prevalence of atrial fibrillation and flutter in the United States. Am J Cardiol. 2009, 104:1534-39. 10.1016/j.amjcard.2009.07.022

4. Go AS, Hylek EM, Phillips KA, Chang Y, Henault LE, Selby JV, Singer DE: Prevalence of diagnosed atrial fibrillation in adults: national implications for rhythm management and stroke prevention: the AnTicoagulation and Risk Factors in Atrial Fibrillation (ATRIA) Study. JAMA. 2001, 285:2370-75. 10.1001/jama.285.18.2370

5. Guo S, Chao ST, Reuther AM, Barnett GH, Suh JH: Review of the treatment of trigeminal neuralgia with Gamma Knife radiosurgery. Stereotact Funct Neurosurg. 2008, 86:135-46. $10.1159 / 000120425$

6. Dagres N, Hindricks G, Kottkamp H, Sommer P, Gaspar T, Bode K, Arya A, Husser D, Rallidis LS, Kremastinos DT, Piorkowski C: Complications of atrial fibrillation ablation in a highvolume center in 1,000 procedures: still cause for concern?. J Cardiovasc Electrophysiol. 2009, 20:1014-19. 10.1111/j.1540-8167.2009.01493.x

7. Marrouche NF, Dresing T, Cole C, Bash D, Saad E, Balaban K, Pavia SV, Schweikert R, Saliba W, Abdul-Karim A, Pisano E, Fanelli R, Tchou P, Natale A: Circular mapping and ablation of the pulmonary vein for treatment of atrial fibrillation: impact of different catheter technologies. J Am Coll Cardiol. 2002, 40:464-74. 10.1016/S0735-1097(02)01972-1

8. Spragg DD, Dalal D, Cheema A, Scherr D, Chilukuri K, Cheng A, Henrikson CA, Marine JE, Berger RD, Dong J, Calkins H: Complications of catheter ablation for atrial fibrillation: incidence and predictors. J Cardiovasc Electrophysiol. 2008, 19:627-31. 10.1111/j.15408167.2008.01181.x

9. Timmerman R, Paulus R, Galvin J, Michalski J, Straube W, Bradley J, Fakiris A, Bezjak A, Videtic G, Johnstone D, Fowler J, Gore E, Choy H: Stereotactic body radiation therapy for inoperable early stage lung cancer. JAMA. 2010, 303:1070-76. 10.1001/jama.2010.261 
10. Videtic GM, Stephans K, Reddy C, Gajdos S, Kolar M, Clouser E, Djemil T: Intensitymodulated radiotherapy-based stereotactic body radiotherapy for medically inoperable earlystage lung cancer: excellent local control. Int J Radiat Oncol Biol Phys. 2010, 77:344-49. 10.1016/j.ijrobp.2014.05.017

11. Blanck O, Bode F, Gebhard M, Hunold P, Brandt S, Bruder R, Grossherr M, Vonthein R, Rades D, Dunst J: Dose-escalation study for cardiac radiosurgery in a porcine model . Int J Radiat Oncol Biol Phys. 2014, 89:590-98. 10.1016/j.ijrobp.2014.02.036

12. Ipsen S, Blanck O, Oborn B, Bode F, Liney G, Hunold P, Rades D, Schweikard A, Keall PJ: Radiotherapy beyond cancer: target localization in real-time MRI and treatment planning for cardiac radiosurgery. Med Phys. 2014, 41:120702. 10.1118/1.4901414

13. Chang JY, Li QQ, Xu QY, Allen PK, Rebueno N, Gomez DR, Balter P, Komaki R, Mehran R, Swisher SG, Roth JA: Stereotactic ablative radiation therapy for centrally located early stage or isolated parenchymal recurrences of non-small cell lung cancer: how to fly in a "no fly zone". Int J Radiat Oncol Biol Phys. 2014, 88:1120-28. 10.1016/j.ijrobp.2014.01.022

14. RTOG 0813 Protocol Information: Seamless Phase I/II Study of Stereotactic Lung Radiotherapy (SBRT) for Early Stage, Centrally Located, Non-Small Cell Lung Cancer (NSCLC) in Medically Inoperable Patients. (2015). Accessed: July 9, 2016: http://www.rtog.org/ClinicalTrials/ProtocolTable/StudyDetails.aspx?study=0813.

15. Stephans KL, Djemil T, Diaconu C, Reddy CA, Xia P, Woody NM, Greskovich J, Makkar V, Videtic GM: Esophageal dose tolerance to hypofractionated stereotactic body radiation therapy: risk factors for late toxicity. Int J Radiat Oncol Biol Phys. 2014, 90:197-202. 10.1016/j.ijrobp.2014.05.011

16. Sharma A, Wong D, Weidlich G, Fogarty T, Jack A, Sumanaweera T, Maguire P: Noninvasive stereotactic radiosurgery (CyberHeart) for creation of ablation lesions in the atrium. Heart Rhythm. 2010, 7:802-10. 10.1016/j.hrthm.2010.02.010

17. Fowler JF: The linear-quadratic formula and progress in fractionated radiotherapy . Br J Radiol. 1989, 62:679-94. 10.1259/0007-1285-62-740-679

18. Park C, Papiez L, Zhang S, Story M, Timmerman RD: Universal survival curve and single fraction equivalent dose: useful tools in understanding potency of ablative radiotherapy. Int J Radiat Oncol Biol Phys. 2008, 70:847-52. 10.1016/j.ijrobp.2007.10.059

19. Videtic GM, Stephans KL, Woody NM, Reddy CA, Zhuang T, Magnelli A, Djemil T: 30 Gy or 34 Gy? Comparing 2 single-fraction SBRT dose schedules for stage I medically inoperable nonsmall cell lung cancer. Int J Radiat Oncol Biol. 2014, 90:203-208. 10.1016/j.ijrobp.2014.05.017

20. Abelson JA, Murphy JD, Loo BW Jr, Chang DT, Daly ME, Wiegner EA, Hancock S, Chang SD, Le QT, Soltys SG, Gibbs IC: Esophageal tolerance to high-dose stereotactic ablative radiotherapy . Dis Esophagus. 2012, 25:623-29. 10.1111/j.1442-2050.2011.01295.x

21. Cox BW, Jackson A, Hunt M, Bilsky M, Yamada Y: Esophageal toxicity from high-dose, singlefraction paraspinal stereotactic radiosurgery. Int J Radiat Oncol Biol Phys. 2012, 83:e661-67. 10.1016/j.ijrobp.2012.01.080

22. Benedict SH, Yenice KM, Followill D, Galvin JM, Hinson W, Kavanagh B, Keall P, Lovelock M, Meeks S, Papiez L, Purdie T, Sadagopan R, Schell MC, Salter B, Schlesinger DJ, Shiu AS, Solberg T, Song DY, Stieber V, Timmerman R, Tomé WA, Verellen D, Wang L, Yin FF: Stereotactic body radiation therapy: the report of AAPM Task Group 101 . Med Phys. 2010, 37:4078-101. 10.1118/1.3438081

23. Gardner EA, Sumanaweera TS, Blanck O, Iwamura AK, Steel JP, Dieterich S, Maguire P: In vivo dose measurement using TLDs and MOSFET dosimeters for cardiac radiosurgery. J Appl Clin Med Phys. 2012, 13:3745.

24. Ernst F, Bruder R, Schlaefer A, Schweikard A: Forecasting pulsatory motion for non-invasive cardiac radiosurgery: an analysis of algorithms from respiratory motion prediction. Int J Comput Assist Radiol Surg. 2011, 6:93-101. 10.1007/s11548-010-0424-9

25. Kim DW, Cho LC, Straka C, Christie A, Lotan Y, Pistenmaa D, Kavanagh BD, Nanda A, Kueplian P, Brindle J, Cooley S, Perkins A, Raben D, Xie XJ, Timmerman RD: Predictors of rectal tolerance observed in a dose-escalated phase 1-2 trial of stereotactic body radiation therapy for prostate cancer. Int J Radiat Oncol Biol Phys. 2014, 89:509-17.

10.1016/j.ijrobp.2014.03.012 